\title{
Tejiendo el consenso desde la combinación de las agendas: la Agenda Melding
}

Gretta Paiz Malespín ${ }^{1}$

\section{Resumen}

Este ensayo tuvo el propósito de consignar el debate de la Agenda Melding, propuesta por sus creadores a manera de hipótesis como una nueva dimensión de la Agenda Setting, desde un renovado planteamiento que pone en el centro a grupos de individuos capaces de crear conexiones unos con otros, a decidirse por una o varias agendas y a constituir las propias.

Esta nueva perspectiva de la Agenda Melding o combinación de agendas, desentelaraña viejas, arbitrarias y cuestionadas posturas como la Teoría de la aguja hipodérmica y la Teoría de la espiral del silencio, desde las cuales los individuos tenían reducidas sus capacidades de pensar y decidir, quedando atrás, el efecto dominante y superpoderoso de los medios de comunicación en fijar la agenda y la prioridad del público sobre ésta.

En efecto, la Agenda Melding ha propuesto un nuevo paradigma teórico, metodológico y pragmático, que conduzca a una nueva era de los medios de comunicación y que estos puedan pasar de posiciones verticales a más horizontales, en la medida que consigan incorporar y priorizar como parte de su agenda la misma de la comunidad, entendida esta como el grupo de individuos en una sociedad.

Palabras clave: Agenda Setting; Agenda Melding; Consenso; Opinión Pública; Audiencia.

\section{Summary}

This essay was intended to reflect on the debate of the Melding Agenda, which was proposed by its creators as a hypothesis to a new dimension of the Setting Agenda, that brings a renewed approach that puts in the center a group of individuals capable to create connections one with another, to decide on one or various agendas and to establish their own.

This new perspective of the Melding Agenda or the combination of agendas, uncovers old, arbitrary and questioned positions such as the Hypodermic Needle Theory and the Theory of the Spiral of Silence, from which the individuals had reduced their

1 Directora del Instituto para la Comunicación Intercultural (ICI-URACCAN), y Estudiante de Doctorado en la Pontificia Universidad Católica de Chile. E-Mail: grettapaiz@uraccan.edu.ni 
capacities to think and decide, leaving behind the dominant and powerful effect that the media has in setting the agenda and thus, the public's priority over it.

In fact, the Melding Agenda has proposed a new theoretical, methodological and pragmatic paradigm, which aims to lead the media's to a new era so that these can advance from vertical to more horizontal positions, to the extent in which they achieve to incorporate and prioritize as a part of their agenda the community's own, understood as the group of individuals in a society.

Keywords: Setting Agenda; Melding Agenda; Consensus; Public opinion; Audience.

\section{Introducción}

Si bien este ensayo no se extiende a la Agenda Setting, resulta imposible discutir la Agenda Melding sin antes detenernos y asegurar un recorrido por la teoría acuñada por McCombs y Shaw (1972), y que dimensionó la capacidad que tenían para la época los medios de comunicación en definir las prioridades, desde los temas que las noticias destacaban y desde el público que también las priorizaba (McCombs y Valenzuela, 2007).

La Agenda Melding propone nuevas posibilidades para mezclar los objetos y atributos del orden del día de una variedad de medios de comunicación para construir una imagen del mundo. Se entiende como la forma en que se consigue equilibrar las agendas de comunidad cívica y nuestras comunidades de referencia valoradas con nuestros propios puntos de vista y experiencias para crear una imagen satisfactoria del mundo (Shaw y Weaver, 2014).

El concepto de Agenda Melding propuesto por Donald Shaw (1999), se centra en cómo las personas mezclan los elementos de una variedad de programas para la construcción de sus imágenes del mundo (Shaw, Hamm y Terry, 2006). La Agenda Melding, si bien no reemplaza el entorno de la agenda de los medios, trata de explicar por qué la fuerza de ajuste de la agenda de los medios varía entre los diferentes medios de comunicación, grupos e individuos.

Consecuentemente, la nueva perspectiva de la Agenda Melding revela viejas y cuestionadas posturas como la Teoría de la aguja hipodérmica de Haroll Laswell (1927), que hacía creer que el mensaje era inyectado sin mediación alguna en la mente del individuo (Camardo, 2015), en abierta alusión a una teoría que otorgaba a los medios la capacidad de manipular directamente a los individuos, debido a la masificación y al aislamiento social en que vivían las personas (Martínez, Juanatey y Costa, 2011). Este último aspecto es congruente con el debate sostenido por Noelle-Neuman (1995), en razón de la Teoría del Espiral del silencio, que llevaba al individuo a callar, frente al temor de sufrir el aislamiento y la exclusión social. 


\section{Metodología}

La revisión bibliográfica se centró en la búsqueda de artículos relacionados a la Agenda Melding utilizando con este propósito bases de datos como Dialnet, Scopus y Scielo, y, revistas especializadas de la Mass Comunication and Society, International Journal of Public Opinion Research, Journalism and Mass Comunication Quarterly, Comunication Quarterly, principalmente. La exploración incluyó artículos originales de investigadores como McCombs, Weaver y Shaw, este último creador de la Agenda Melding, definida como una teoría de la disonancia social, en alusión a la hipótesis de la disonancia cognitiva (Festinger, 1957).

El recorrido por bases de datos relevantes evidencian que los estudios se desarrollan enfocados en gran medida en cómo se produce la transferencia de atributos posicionada por la Agenda Setting, y no en esta nueva perspectiva de la Agenda Melding, en donde la audiencia fija sus propios temas y agendas. La estrategia de búsqueda de información, permitió analizar bases de datos en español e inglés, en las que se localizaron contenidos escasamente relacionados a la Agenda Melding. Si bien, no es posible analizar la combinación de las agendas al margen de la Agenda Setting, la Agenda Melding, no se presenta todavía como una dimensión explorada desde la investigación.

La revisión bibliográfica es guiada por interrogantes claves para entender en qué consiste la Agenda Melding. ¿Qué se entiende por Agenda Melding? ¿Es otro nivel de la Agenda Setting? ¿Es una nueva teoría? o ¿Es una hipótesis de la Agenda Setting que permitiría explicar cómo las audiencias consiguen consensuar y priorizar agendas y temas? Desde esta perspectiva es un esfuerzo que se concentró en discutir la principal bibliografía relacionada a la Agenda Melding.

En el proceso de búsqueda se analizaron resúmenes, introducciones, artículos y capítulos de libros dedicados a la Agenda Melding.

\section{Discusión}

\section{Concepto, discusión y evolución de la Agenda Setting}

Para Casemeiro, De La Torre y Téramo (2009) la Agenda Setting es una descripción y explicación de la influencia que las noticias y que los medios de comunicación producen en la opinión pública. Al respecto McCombs (2004), confirma que particularmente se trata de la influencia de un conjunto de noticias sobre la percepción del público, y de cuáles son los temas más importantes del día. En relación a este concepto, Bahamondes (2014) sostiene que la Agenda Setting analiza cómo los medios de comunicación masivos establecen agendas temáticas que construyen la realidad social. Este punto va 
a cobrar bastante fuerza al momento de analizar en qué circunstancias se pone en el debate la nueva dimensión de la Agenda Melding.

En definitiva, la idea central de la teoría de la Agenda Setting, de transferir relevancia o prominencia de una agenda a otra (McCombs, 2004), se convierte en la propia necesidad de ir por nuevas áreas de aplicación y desarrollo (McCombs y Valenzuela, 2007). La postura de los teóricos es consistente con la idea de asumir la Agenda Melding como una nueva posibilidad de analizar ya no los efectos que los medios desencadenan en la ciudadanía, sino las nuevas relaciones que se están produciendo entre ciudadanos que han decidido ir en busca de sus propias agendas. Este aspecto es clave para entender por qué se hace oportuno comenzar a pensar en nuevas prioridades desde los estudios que hasta hoy parecieran que han estado aludiendo a los efectos de los medios en la opinión pública y marginalmente cuáles son los cambios que están produciéndose en esa ciudadanía. Este es el punto de inflexión que le da valor a la Agenda Melding.

En este mismo escenario, autores como López García (2004), insisten en seguir viendo a los medios de comunicación como auténticos mediadores entre los líderes y el público, y de encargarse de establecer las coordenadas del debate público. Sin embargo, esta posición es rebatible en la medida que no deslegitime las iniciativas y capacidades que tendrían las propias audiencias al momento de seleccionar una o varias agendas, más allá de las propias fronteras de los medios tradicionales de comunicación. De allí que la Agenda Melding, tome prominencia en realidades en donde se requieren procesos inclusivos y medios horizontales que lleven al reconocimiento de todos los actores en una sociedad.

Un punto de inflexión en el debate se produce cuando el autor de la Agenda Setting consigna opinión pública, relacionada por Habermas (2003), a gente que habla entre sí, que pone en circulación sus opiniones y contribuye a la formación de un tejido social específico. En este punto resulta interesante tratar de entender cómo esa opinión pública, explicada por Habermas como una parte de la sociedad que se despoja de todo y accede a un ámbito de la esfera pública para compartir y opinar de los temas que le preocupan, incide inexplicablemente para que otra parte de la gente opine, se forme pensamientos sobre los asuntos públicos y contribuya a construir esa parte sustancial de la realidad social (Mora, 2005).

Otra perspectiva a considerar es la que Walter Lippman (2003) discute, argumentando que la opinión pública responde a un seudo-entorno construido por los medios informativos, influenciado entre otros factores, por la propaganda política, las imágenes individuales, el egocentrismo, la manipulación, y la experiencia de mundos y realidades no disponibles directamente (Rubio 2004). La visión de Lippman, desde el reconocimiento que se está produciendo un nuevo espacio público quedaría 
desestimada, en tanto, se evidencian las capacidades y las iniciativas de un público que no es pasivo, sino activo, que propone, discute, analiza, critica, se moviliza.

La nueva discusión por la Agenda Melding enciende la polémica de lo que se entiende hoy por opinión pública en un debate desafiado hace muchos años por Habermas, Lippman y Noelle-Neuman.

\section{El término "agenda" y los elementos que la componen}

El término agenda es acuñado por Rodríguez (2004) para expresar de qué manera los temas considerados relevantes por los medios pasan a ser subrayados también en las agendas de las audiencias. En este sentido, las personas no sólo reciben información a través de los medios sobre determinados temas o asuntos que ocurren en el mundo y son considerados prioritarios, sino que también aprenden de ellos la importancia y el énfasis que les deben dar.

En su tesis tributada a la Agenda Setting, Rodríguez dedica un apartado a explicar lo que se entiende como agenda y a los elementos que la componen, a saber, (1) los temas o issues, y (2) la relevancia (salience). De acuerdo a la autora, dentro de las agendas son muchos los temas que aparecen en ellas, pero no todos tienen la misma importancia ni tampoco a todos se les da el mismo tipo de relevancia (Rodríguez, 2004).

Acertadamente, Rodríguez se ha referido a la manera que tienen los medios de comunicación de decidir darle prioridad a un tema por encima del otro, o en muchos casos dejarlos afuera de la agenda. Esto es consistente cuando se confirman hechos trascendentales que ocurren todos los días, pero éstos no llegan a ser transferidos con igual importancia a la agenda mediática. Hacer un tema visible o invisibilizado necesariamente tiene que ver con la configuración de las agendas en el seno de los medios de comunicación, y en este sentido, la Agenda Melding está diciendo que los medios al excluir esos temas, está excluyendo que la gente conozca lo que está pasando.

Aquí precisamente nace el desafío de medios de comunicación para referirse a aspectos desde una agenda más incluyente y una estructura mediática que incorpora los temas que también son importantes desde la comunidad. Esto se traduce a que los medios de comunicación, sus directores de prensa y periodistas están llamados a incentivar relaciones de consenso que aseguren integrar los temas de las comunidades como una parte fundamental y complementaria a la agenda del medio. El reto se formaliza en la propuesta de liderar iniciativas investigativas en contextos donde los medios de comunicación en general (prensa, radio, televisión, redes sociales, entre otros), dejen de invisibilizar los asuntos que desde las sociedades registran significancia. 


\section{Una mirada crítica al proceso de establecer la agenda}

A mediados de los años 8o, Dearing y Rogers (1996), durante la Conferencia de Investigación de la Opinión Pública (1986) y a la luz de un proceso de revisión crítica de la Agenda Setting, consiguieron establecer que los tres componentes principales en el proceso de establecer esta: a) La agenda de los medios, b) La agenda pública, y c) La agenda política.

La crítica sostenida por ambos autores en ese momento suponía que la Agenda Setting, integrada por estas tres agendas, no conseguía definir una interrelación entre estos tres elementos. Muy al contrario, lo que había promovido como tradición, era implementar investigaciones por cada una de ellas. En conclusión, proponen que la Agenda Setting se entiende mejor como un proceso de interacción entre los tres tipos de agendas.

El planteamiento de Dearing y Rogers habría tenido eco años posteriores cuando posturas como la de López (2006) lo llevan a considerar que efectivamente las continuas revisiones, si bien no invalidaban la base teórica de la Agenda Setting, redundaban en su indefinición. Sin embargo, una nueva dimensión de la discusión, a la luz de una nueva opinión pública propuesta desde la Agenda Melding, dejaría sin efecto la aparente dicha indefinición.

Al debate de Dearing, Rogers y López se une Fenoll (2009), consignando que el nuevo escenario digital está modificando significativamente la forma en que los medios tradicionales se relacionan con su audiencia y por consiguiente, la base sobre la que se sustenta la teoría de la Agenda Setting.

El surgimiento de la nueva propuesta de la Agenda Melding, vendría a confirmar la teoría de este ensayo, es decir, que si bien se produce una evolución del modelo de la Agenda Setting capaz de responder a las características del nuevo entorno tecnológico y social, se está produciendo significativamente un cambio en una audiencia que está siendo capaz de buscar entre otras agendas de otras audiencias, las de su propias preferencias, llevándolas por ende a combinar.

Weaver, McCombs y Shaw (2004) analizan el impacto que produce la Agenda Setting en la investigación en comunicación de masas. Tienen un interés especial en analizar cómo desde la Agenda Melding se produce un efecto contrario, al que origina la Agenda Setting para la opinión pública, llevándolos a revisar brevemente el nuevo concepto de la teoría de la Agenda Setting y la teoría de la disonancia social, propuesta por Donald Shaw, y desde la cual se centra el análisis de la Agenda Melding, para tratar de explicar por qué algunas personas pueden adoptar diferentes agendas. 


\section{Los nuevos escenarios en la investigación}

En un principio, los estudios relacionados con la teoría de la Agenda Setting estaban enfocados en constatar de qué manera el grado de énfasis incorporado a los temas por las informaciones influía en la prioridad que les concede a dichos temas el público (Odriozola, 2012). En este contexto, una perspectiva novedosa presentada por Rodríguez (1999) lleva a la Agenda Setting al ámbito educativo y consigue derribar el muro de hierro de la tradicionalidad de los estudios enfocados desde esta teoría. Su investigación desde una nueva propuesta de agenda-setter demuestra que si bien el profesor juega un rol esencial en el proceso enseñanza aprendizaje en el aula de clases, una gran parte de los temas que configuran la agenda de los estudiantes no coincidía con la relevancia que otorgaba el profesor a esos mismos aspectos y atributos.

La autora de la tesis: Teoría de la Agenda-Setting: aplicación a la enseñanza universitaria, consigue situar a la propia Agenda Setting en otro nivel del debate incorporando una metodología novedosa desde la cual investigó al grupo de estudiantes (en un nivel de audiencias) y a los profesores (como medios de comunicación). Desde la teoría setting se enfocó en indagar cuáles eran los temas y atributos que los estudiantes asignaban a cada materia (como agenda de los estudiantes y el grado de prioridad que dan a cada uno de ellos). Rodríguez (2004) consiguió extrapolar la idea de relevancia planteada por la Agenda Setting a la relación comunicativa en la enseñanza superior. El docente es transformado en una variable indispensable en el proceso de formación y a la vez el que ejerce la acción de definir y seleccionar los temas (Agenda Setter).

McCombs y Funk (2011), al relacionar metafóricamente la Agenda Setting y la estructura comunitaria como pasajeros de un mismo tren, y un tren que ofrece las noticias diarias, reivindican la necesidad de identificar desde las investigaciones cómo se establece la agenda informativa de los medios y qué decisión tienen los periodistas al momento de proponer un tema para que se integre a la agenda del medio. Sádaba y Rodríguez (2007) también se refieren a la importancia de poder identificar con claridad cómo y quién establece esta agenda.

La discusión precedida por los autores es fundamental para identificar con claridad los desafíos que se desprenden para los procesos de investigación en el contexto de los medios de comunicación y Agenda Setting, indistintamente de sus niveles y dimensiones. Implica romper con la tradición investigativa de la Agenda Setting, identificando en otros ambientes (interculturales, medioambientales, sociales, entre otros), los factores que influyen en la cobertura informativa de los asuntos públicos en los medios de comunicación en general (radio, prensa, televisión, redes sociales, otros).

En su artículo, Flores Roa (2012) asegura que la investigación en torno al fenómeno de la Agenda Setting sigue proponiendo elementos y factores que ayudan a comprender y a encontrar los límites dentro del proceso de los medios informativos. 
La Agenda Melding superaría para algunos autores las limitaciones de la Agenda Setting, en cuanto que contempla todas las fuentes que intervienen en el proceso de establecimiento de agenda del público como sus relaciones interpersonales o las nuevas formas de comunicación surgidas de las nuevas tecnologías de la información y la comunicación, cuyo producto influye en la agenda final que el público adopta (Camargo, 2015).

Autores como Camargo (2015), justifican el surgimiento de la Agenda Melding en un nuevo entorno tecnológico y social, dado que los actores que intervienen en la Agenda Setting han mutado, y esta mutación exige una evolución del modelo capaz de responder a las características de un nuevo contexto en el que la audiencia amplió la configuración de su agenda a más medios de comunicación, y donde la Internet se posiciona como otra fuente de información en el que se mezclan las distintas agendas.

\section{La Agenda Melding: su concepto y orígenes}

La Agenda Melding es un término acuñado por Donald Shaw en 1999 (Shaw, McCombs, Weaver y Hamm, 1999). Shaw y Colistra (2008), definen la Agenda Melding como un proceso que conduce a los individuos a buscar y mezclar las agendas originadas en distintos medios de comunicación adaptándolas a sus preferencias y conocimientos individuales. De acuerdo a los investigadores, mientras la Agenda Setting se centra en el poder de los medios para establecer agendas; la Agenda Melding evoca a la capacidad de los miembros de la audiencia para seleccionar entre los medios de comunicación, problemas y los elementos de los mensajes.

Asimismo, que cuando las personas se unen a grupos a pesar de que estos individuos pueden tener diferentes orígenes, tienden a fusionar sus agendas con la agenda global del grupo (McCombs, Shaw y Weaver, 2014). Los individuos se ven motivados a unirse a grupos, afiliarse a organizaciones o pertenecer a colectivos sociales para evitar el dilema de vivir en el aislamiento intelectual y enfrentar la ambigüedad en un mundo complejo e interconectado (Shaw, McCombs et al., 1999).

Lo cierto es que, para que los individuos consigan pertenecer a un determinado grupo necesariamente tendrían que buscar y conocer los distintos niveles de agendas que interaccionan en el marco de su propio entorno. En "Individual Groups, and Agenda Melding: A Theory of Social Dissonance", Shaw, McCombs, Weaver y Hamm, (1999), al analizar los hallazgos consignados en estudios anteriores dan cuenta, que existe un grado de audiencia aprendiendo de los medios de comunicación, pero en particular, de los nuevos temas incorporados por las noticias, situación que los lleva a reconocer la necesidad de emprender estudios desde el efecto de fijar la agenda a niveles más profundos y más allá de las categorías de noticias generales. Esta es una consideración que los autores hacen a la luz de que existe un público que absorben los atributos de las noticias, los marcos, pero también los sesgos que se presentan en las noticias. 
De acuerdo a los autores, la Agenda Melding, argumenta que las personas se unen a grupos en cierto sentido, al unir las agendas; se produce una necesidad de afiliarse a otros en grupos a través de las uniones que se dan mediante los medios de comunicación, creándose por consiguiente una conexión con otras personas, y con otros, a otros medios de comunicación. El artículo sugiere un modelo de combinación de agenda que reconfigura el papel de los medios de comunicación en la proporción que conduce a los individuos a desplazarse hacia o lejos de los grupos. En el fondo, la Agenda Melding está advirtiendo en cómo los individuos funcionan con otros en un sistema social coherente y menos fraccionado de lo que se cree.

\section{La necesidad de la orientación}

Conceptualmente la Agenda Melding, puede asumirse como una hipótesis que permitiría explicar cómo los individuos buscan información para posicionarse dentro de los grupos sociales (Shaw, McCombs, Weaver y Hamm,1999), en abierta alusión a la necesidad de orientación, que lleva a las personas a motivarse por entrar en contacto con lo que ocurre a su alrededor (Aruguete, 2015), frente a un escenario desconocido se esfuerzan por orientarse, generando mapas cognitivos que les permitan llenar dichos vacíos en el conocimiento (McCombs y Weaver, 1973).

Al respecto McCombs (2006), manifiesta que la Agenda Melding desarrolla el concepto de la necesidad de orientación y explica por qué las personas pueden encontrar unas agendas más relevantes que otras; a saber: debido a su afiliación con determinadas comunidades o grupos. En este escenario teórico se comparan las agendas personales con un gran abanico de otras agendas que van desde los medios de difusión y los sitios web de mayor acceso a otros individuos.

En cambio para Flores (2012), la necesidad de orientación no sólo responde al grado de incertidumbre sobre determinados temas relevantes al individuo sólo por su experiencia personal, sino también en lo que concierne a los temas que determinado grupo considera relevante y a la información que sobre ellos requiere el individuo para pertenecer a determinado grupo. De allí que la posición de Fenoll (2009), sea de considerar la Agenda Melding centrada en la agenda personal del público y que tenga en cuenta la relación que mantiene el individuo con su entorno y con otros individuos con los que comparte intereses a la hora de establecer su propia agenda.

Ragas y Roberts (2009), en su artículo: "Agenda Setting and Agenda Melding in an age of Horizontal and Vertical Media: a new theoretical Lens for Virtual Brand Communities", sostienen que el planteamiento de los autores es que la Agenda Melding se produce cuando las personas se unen a grupos y fundan sus propias agendas personales con la agenda del grupo. Por tanto, las personas que ya forman parte de una comunidad decidirán adoptar un grupo de puntos de vista o caer en el silencio, en abierta alusión a la Teoría de la Espiral del Silencio. 


\section{Los individuos y la Teoría de la Disonancia Social}

McCombs, Shaw y Weaver (2014), sostienen que un poco de fuerza en los individuos impulsa a buscar y adoptar grupo o grupos para pertenecer a una comunidad de agendas, reconociendo que si bien la Agenda Setting es una parte importante, representa sólo una parte de la intervención de este proceso social de la Agenda Melding que procura eliminar la disonancia de vivir en aislamiento intelectual una vez que las personas deciden buscar en las agendas de otros grupos que deciden unirse.

La Teoría de la Disonancia Social alude a una unidad y conduce a los grupos a unirse, y en la medida que esto se produce también se registra la combinación de las agendas, explican los autores que cuando los grupos se fusionan, se están uniendo a una agenda de temas definidos como el conjunto de prioridades que atrae a las personas que buscan evitar el aislamiento social (Shaw, McCombs, Weaver y Hamm, 1999).

Para Ragas y Robert (2009), la Teoría de la Disonancia Social se basa en el hecho de que las personas al buscar información, evitan que entre en conflicto con sus propios puntos de vista. De acuerdo a Shaw et al., (1999), los individuos que experimentan la necesidad de vincularse a grupos husmean información sobre los colectivos de personas, medios de comunicación y su propia experiencia.

En materia de la Agenda Melding, los estudios demuestran que las personas valoran y se unen a grupos que dedican tiempo para convencerlos a valorar las cosas más importantes. Si los recién llegados no se ajustan, se hacen esfuerzos para convencerlos de la importancia de la agenda del grupo, pero si eso no funciona, los individuos de un grupo colectivamente rechazan al miembro no conforme. Por consiguiente, la disonancia se produce cuando estos valores y las agendas constantemente son desafiados por individuos que no están en condiciones de pertenecer al grupo sin posiciones disidentes.

\section{La Agenda Melding y la transferencia de atributos}

Con New Directions in Agenda-Setting. Theory and Research, McCombs, Shaw y Weaver (2014), presentan un balance de la Agenda Setting en sus distintos niveles; la transferencia de relevancia (en el primer nivel de la agenda), la transferencia de atributos (en el segundo nivel de la agenda), y consiguen explorar con mayor prominencia la Agenda Melding o la combinación de agendas.

A partir de un experimento, estos autores consiguen identificar que la Agenda Melding, es consistente con el segundo nivel de la agenda (transferencia de atributos), en la medida que encuentran que es una agenda para interactuar desde medios y agendas más horizontales. Por consiguiente, agendas más incluyentes y articuladoras del consenso. Caseimero, De la Torre y Téramo (2009), definen los atributos como 
los aspectos de un tema que resultan enfatizados por los medios de comunicación periodística.

Parafraseando a McCombs, Shaw y Weaver (2014), la Agenda Melding está centrada en las agendas personales de los individuos en relación con su comunidad, con quien experimentan un proceso íntimo y a menudo inconsciente. El concepto utilizado por los teóricos, da cuenta que la Agenda Melding es el proceso social por el cual se agrupan temas de fuentes distintas, incluyendo a otras personas, para crear un retrato del mundo que se ajuste a sus aprendizajes y preferencias.

Con este trazado teórico, una comunidad en la agenda, en cierto modo, es la comunidad, en la medida que son los propios medios de comunicación los que dan cobertura a las comunidades donde se vive, trabaja y divierte. Mientras la Agenda Setting representa un intercambio de prominencias, la Agenda Melding, describe el proceso por el que se toma prestada una variedad de agendas personales o creadas por las comunidades en que se elige vivir (McCombs, Shaw et al, 2014).

Una contribución a los estudios de la Agenda Setting, es la propuesta que hace Camardo (2006), al momento de medir qué sucede con la agenda del público cuando éste se informa a través de Internet. Su principal hipótesis apunta a pensar que el uso de medios digitales como fuente de información es una variable que incide en las condiciones circunstanciales privando el efecto agenda. De acuerdo a la autora, los medios digitales sin dudas, han de haber modificado algo de lo que percibimos e imaginamos del mundo.

\section{La Agenda Melding y la pertenencia de los individuos}

Uno de los aspectos significativos del debate propuesto por Shaw, McCombs, Weaver y Hamm (1999), es la pertenencia de la audiencia, desde la lógica de que si bien es posible medir la Agenda Setting sólo a partir de la exposición mediática, ésta tiene sus orígenes en la necesidad de pertenencia de los individuos, quienes buscan activamente pertenecer a grupos para poder sentirse parte de la sociedad.

En este sentido, el punto de conexión de los grupos conformados por distintos individuos, son reglas, valores actitudes y opiniones, que les rige y al mismo tiempo transfieren al resto de sus integrantes, en una dinámica que los lleva a adoptar también la agenda de la comunidad como factor determinante sobre la necesidad de orientación (Shaw, McCombs et al, 1999).

En definitiva, la pertenencia de los individuos que se produce con la Agenda Melding, interpela a los grupos a compartir, aceptar y regirse por reglas y valores, atraer a nuevos integrantes y mezclar sus agendas con las de los grupos a los que pertenecen. Shaw, McCombs y Weaver, están diciendo que la combinación no es un 
proceso nuevo dado que se está llevando a cabo todo el tiempo en la sociedad. Por consiguiente, es sólo una parte de esfuerzo que hacen los individuos para poder pertenecer y aprender más sobre los grupos que les interesan.

En su artículo enfocado a la Agenda Melding, Coleman, McCombs, Shaw y Weaver (2009), consignan una creciente evidencia de que el público consigue mezclar las agendas de varios medios de comunicación, produciéndose por consiguiente, que tanto el público como las agendas de los medios se combinen, influenciados en el fondo por una mezcla de agendas. A juicio de los autores, si bien la Agenda Setting establece una conexión entre el medio y la audiencia, los nuevos estudios en el tema, están incorporando las opciones de las audiencias y los medios de comunicación que hacen dentro de la hipótesis general el establecimiento de la agenda.

La premisa es que son audiencias que tienen opciones, propuestas y necesidad de orientación que consiguen resolver a partir de los valores y actitudes que le son propias a cada individuo y que les resulta factible utilizar una variedad de medios especializados que se adaptan a sus estilos de vida personales y puntos de vista, tales como programas de conversación en radio o de televisión.

La investigación de la Agenda Setting ha establecido que periodistas y editores tienen gran poder de influencia para dar forma a los principales temas de importancia para el público, junto con muchos detalles de esos temas. Con esta condición, los medios de comunicación tienen la alternativa de reconocer la importancia que la estructura de la comunidad imprime a los temas que dan sentido a las noticias de los periódicos locales y nacionales.

\section{Los ingredientes para la Agenda Melding}

En el estudio New Direction in Agenda-Setting Theory and Research, McCombs, Shaw y Weaver (2014), profundizan en una Agenda Melding que para considerarla debe contener como ingredientes 1) Información sobre la comunidad cívica (representa a todo el pueblo), 2) Información sobre las comunidades (de personas o intereses), y 3) Los intereses personales, las experiencias y las creencias, que son incorporados en las historias, relatos, artículos y reportajes.

En el fondo, el planteamiento es que solamente vamos a presumir que estamos ante la presencia de la Agenda Melding, si en este proceso se incluye y considera la información que se construye desde la comunidad cívica como el mecanismo de representación del pueblo, personas, intereses, experiencias y creencias como parte de la narrativa y la historia de la ciudadanía o los grupos de individuos. 


\section{Los elementos de la Agenda Melding}

A partir del esquema incorporado, los autores reconocen en la Agenda Melding, grandes potenciales desde el mismo momento en que tiene como objetivo, procurar un consenso que se articula desde estos tres elementos, consignados en la siguiente figura:

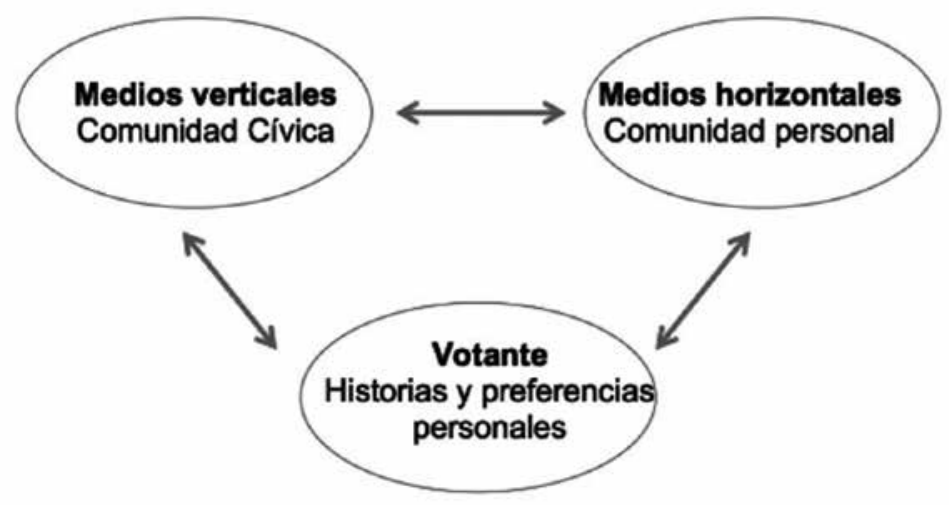

Figura no. 1. McCombs, Shaw y Weaver (2014). Traducción Propia.

El modelo manifiesta una distinción clave hecha por la Agenda Melding y desde la que reconoce que efectivamente existen medios de comunicación verticales, que llegan a través de muchos estratos de la sociedad para construir un público masivo y medios de comunicación horizontales, que buscan un público con intereses especiales o puntos de vista específicos.

A juicio de Shaw y Weaver (2014), se entiende como medios verticales los que proporcionan la agenda principal de noticias de la vida pública, y como medios de comunicación horizontales, los que suministran la información de apoyo y perspectivas que complementan la agenda vertical.

En definitiva, la Agenda Melding está planteando la necesidad, sino la urgencia, de direccionar el ejercicio y las prioridades de los medios, a hacer de la comunicación, un espacio más plural, divergente y convergente de las agendas del público, desde lo que está llamando medios horizontales.

Este nuevo escenario de la opinión pública y de los espacios públicos discutidos a la luz de la Agenda Melding, se pone en evidencia no sólo que los grupos de individuos están cambiando, que han ido a la búsqueda de sus propias agendas y medios, sino también, los desafíos de los medios verticales, históricamente dominantes y limitados a una agenda básicamente política. 
En efecto, con la Agenda Melding, los temas culturales, interculturales, identitarios, sociales, medioambientales, educativos, las historias de vida, individuales y colectivas, tienden a ser tomadas en cuenta con mayor prominencia, en un ejercicio interesante que llevaría a los medios a visibilizar otras dimensiones de la vida en comunidad y desde la comunidad.

\section{A manera de conclusión}

La perspectiva de la Agenda Melding representa una conclusión importante a las explicaciones ofrecidas por los autores que dan cuenta que las personas utilizan los medios de comunicación motivados por distintos factores la profundidad de procesamiento de la información que se produce cuando se enfrentan a los medios de información se combinan para crear efectos individuales.

El debate propuesto sobre la Agenda Melding denota que si bien los medios de comunicación presentan transformaciones significativas, la opinión pública y los grupos de individuos también han cambiado, es más activo, ya no se queda con la agenda tradicional de un medio, hoy busca y combina otras, pero también define la propia. Por tanto es desafiante considerar nuevas perspectivas para analizar estos cambios.

Desde los elementos registrados en este ensayo, se hace impostergable que los medios de comunicación, editores y periodistas, reconfiguren una agenda que revierta las etapas de profunda invisibilización de los temas esenciales desde amplios sectores de la sociedad, en una decisión que asegure integrar con igual significación otros temas, procesos construidos desde las propias audiencias, grupos o comunidades.

En tanto, la Agenda Melding evidencia la oportunidad que tienen los medios de comunicación en general, de revertir las brechas desde donde las propuestas de amplios sectores se mueven dentro de los límites de una agenda cuyo paradigma ha sido dominante y excluyente. En los casos que no consignan los medios como parte de su agenda mediática, la Agenda Melding, está diciendo que los medios al excluir esos temas, se está excluyendo a que la gente conozca lo que está pasando.

Uno de los puntos de inflexión que hace a un tema visible o invisibilizado tiene que ver con la configuración de las agendas en el seno de los medios de comunicación. En este escenario, la Agenda Melding está desafiando a los medios de comunicación a transparentar el liderazgo, despojarse de sus sesgos y ser incluyentes al momento de transferir relevancia a los temas con los que construyen sus agendas.

La Agenda Melding se presenta como una nueva posibilidad de llevar la relación de la Agenda Setting, mucho más allá de la simple transferencia de atributos de una agenda a otra, en una dimensión comprensible de esta, y de posicionar nuevas oportunidades que tienen los medios de comunicación en propiciar nuevas relaciones 
de consenso que los lleven a incorporar la agenda de las comunidades como parte fundamental y complementaria a la agenda del medio.

En definitiva, hay una apuesta por la comunidad y desde la comunidad, en esa relación de consentimiento que puede llevar la Agenda Melding, es inevitable pensar entonces, qué no ha funcionado bien para que el consenso se dé en todos los niveles de la Agenda Setting, a juzgar también por su trascendencia, a cincuenta años del primer artículo que llevó a la Agenda Setting a conocerse públicamente.

Finalmente, se sugiere profundizar en la investigación empírica de la Agenda Melding, en aras de valorar la utilidad de ésta al momento de tratar de analizar temas relacionados a cómo los medios de comunicación son capaces de incorporar la agenda de las organizaciones y de la sociedad, cosa que no ocurre con la Agenda Setting en el sentido de que lo que no está en la agenda, no existe.

\section{Lista de referencias}

Aruguete, N. (2015). El Poder de la Agenda. Política, Medios y Público. Editorial Biblos/ Cuadernos de Comunicación.

Bahamondes, M. A. (2014). Agenda Setting.

Casermeiro, A., De la Torre y Téramo (2009). Buenos Aires elige presidente: un estudio en el marco de la teoría de la agenda setting. Educa.

Coleman, R, McCombs, M, Shaw, D, y Weaver, D. (2009). Agenda Melding.

Camardo, S. (2015). Agenda Setting y Medios Digitales: Hacia un paradigma transaccional de la información.

Dearing J, y Rogers, E. (1996). Agenda Setting.

Festinger, L. (1957). A Theory of Cognitive Dissonance. Stanford University Press.

Fenoll, V. (2009). Agenda-Setting y Ciberperiodismo: El caso de la Fórmula 1 en los cibermedios valencianos.

Flores, R, M. (2012). La cobertura del caso Colosio a través de 24 horas: su impacto en la Opinión Pública.

McCombs M, y Weaver (1973): Voter's need for orientation and use of mass communication, Anual Meeting of the International Communication ASSN, Montreal: 1-17. 
McCombs M, y Evatt, D. (1995). Los temas y los aspectos: explorando una nueva dimensión de la agenda setting. Comunicación y Sociedad, Vol. VIII, No. 1. Universidad de Navarra, pp. 7-32.

McCombs, M.(2004). Setting the Agenda: The Mass Media and Public Opinion.

McCombs, M.(2004). Prólogo. En: Rodríguez, Díaz, R. (2004). Teoría de la AgendaSetting: aplicación a la enseñanza universitaria.

Martínez, Juanetey, Orosa, y Rodríguez. (2005). La Teoría de Noelle-Neuman sobre "La Espiral del Silencio" aplicada a las audiencias de la "Telebasura". Comunicación 21, pp. 435-449.

Mora, M. (2005). El Poder de la Conversación. Elementos para una teoría de la opinión pública. Buenos Aires, La Crujía Ediciones.

McCombs, M.(2006). Estableciendo la agenda. El impacto de los medios en la opinión pública y en el conocimiento. Barcelona, Paidós.

McCombs M, y Valenzuela S. (2007). The Agenda Setting Theory. Cuadernos de Información, No. 20, pp. 44-50.

McCombs, M, Funk, M. (2011). Shaping the Agenda of Local Daily Newspapers: A Methodology Merging the Agenda Setting and Community Structure Perspectives. Mass Communication and Society. 14:6, pp. 905-919.

Martínez, Juanatey y Costa. (2012). Agenda setting y crisis económica: Influencia de la prensa en el comportamiento de consumo y ahorro. Estudios sobre el Mensaje Periodístico. Vol. 18 Núm (2012), pp. 147-156.

McCombs, Shaw, y Weaver. (2014): New Directions in Agenda-Setting Theory and Research. Mass Communication and Society. 17:6, pp. 781-802.

McCombs, M.(2014). Setting the Agenda: Mass Media and Public Opinion. Cambridge, England: Polity.

McCombs, M, y Stroud, N. (2014). Psychology of Agenda Setting Effects. Communication Research. Vol.2 (1), pp. 68-93

Noelle-Neuman, E. (1995). La espiral del silencio. Opinión pública: nuestra piel social. Barcelona, Paidós.

Laswell, H.D. (1927). Propaganda Tecniche in the World War. Londres, Knopf Press. 


\section{CIENCIAS SOCIALES}

Lippmann, W. (2003). La opinión pública. Madrid, Langre.

López, G, G. (2003). Estrategias informativas y recepción mediática: la invasión de Irak de 2003. Comunicar, 22. Revista Científica de Comunicación y Educación; pág 89-94.

López, G, G. (2004). Comunicación Electoral y Formación de la Opinión Pública: Las Elecciones Generales de 2000 en la Prensa Española.

Lee K, L,. (2004). Handbook of Political Communication Research.

Lee, K. \& Holtz-Bacha (Eds.). Encyclopedia of political communication, pp. 12-13. Thousand Oaks, CA: SAGE Publications, Inc.

López, G, G. (2006): Teorías Contemporáneas.

Shaw, McCombs, Weaver y Hamm (1999). Individual, Groups, and Agenda Melding: A Theory of Social Dissonance. International Journal of Public Opinion Research Vol. 11. No.1, pp. 2-24.

Shaw D, Hamm B y Terry T. (2006): Vertical vs horizontal media. Military Review, 86 (6), pp. 13-25.

Stecconi, N. (2006). Del Mito de la Caverna a la Teoría del Framing: Una lectura de la obra que instituyó el discurso predominante en la relación entre los mass-media y la opinión pública. pp. 105-120.

Sádaba, T., y Rodríquez, V., (2007). La construcción de la agenda de los medios. El debate del estatut en la prensa española. Ámbitos, No. 16, pp.187-211.

Shaw, D., y Colistra, R. (2008). Agenda melding.

Shaw D, Weaver D. (2014). Media agenda setting and audience agendamelding.

Ragas, M. y Roberts M. (2009). Agenda Setting and Agenda Melding in an age of Horizontal and Vertical Media: a new theoretical Lens for Virtual Brand Communities. Journalism and Mass Communication Quarterly, 86, No. 1, pp. 45-64.

Rodríguez D. (2009). La agenda de los alumnos en clase, profesores como medios y agenda-setting. Estudios sobre el Mensaje Periodístico. 15, pp.431- 442.

Rubio F. J. (2009). Opinión Pública y medios de comunicación. Teoría de la Agenda Setting. Gazeta de Antropología. 25 (1), artículo 01. 
Rodríguez D. (2004). Teoría de la Agenda-Setting: aplicación a la enseñanza universitaria. Observatorio Europeo de Tendencias Sociales.

Odriozola, J.(2012). Cibermedios y agenda-setting: La configuración de la agenda mediática internacional. Estudios sobre el Mensaje Periodístico. Vol. 18 Núm. 1, pp. 157-171.

Weaver, McCombs, y Shaw (2004). Agenda-Setting Research: Issues, Attributes, and Influences.

Wahl-Jorgensen y Hanitzsch (2009). The Handbook of Journalism Studies. 